\title{
Intra- and Trans-Cellular Delivery of Enzymes by Direct Conjugation with Non-Multivalent Anti-ICAM Molecules
}

Rasa Ghaffarian $^{\mathrm{a}}$, Niksa Roki ${ }^{\mathrm{a}}$, Abraham Abouzeid ${ }^{\mathrm{c}}$, Wyatt Vreeland $^{\mathrm{c}}$, Silvia Muro ${ }^{\mathrm{a}, \mathrm{b}}$

\author{
${ }^{a}$ Fischell Department of Bioengineering, University of Maryland, College Park, MD, U.S.A.; \\ ${ }^{\mathrm{b}}$ Institute of Bioscience \& Biotechnology Research, University of Maryland, College Park, MD, U.S.A. \\ ${ }^{c}$ National Institute of Standards and Technology, Gaithersburg, MD, U.S.A.;
}

Short title: Intra- and trans-cellular enzyme transport by monomeric anti-ICAM

\section{Correspondence:}

Silvia Muro

5115 Plant Sciences Building

University of Maryland

College Park, MD 20742

Tel +1 301-405-4777

Fax +1 301-314-9075

Email muro@umd.edu 


\begin{abstract}
Intercellular adhesion molecule 1 (ICAM-1) is a cell-surface protein overexpressed in many diseases and explored for endocytosis and transcytosis of drug delivery systems. All previous evidence demonstrating ICAM-1-mediated transport of therapeutics into or across cells was obtained using nanocarriers or conjugates coupled to multiple copies of anti-ICAM antibodies or peptides. Yet, transport of therapeutics linked to non-multivalent anti-ICAM ligands has never been shown, since multivalency was believed to be necessary to induce transport. Our goal was to explore whether non-multivalent binding to ICAM-1 could drive endocytosis and/or transcytosis of model cargo in different cell types. We found that antiICAM was specifically internalized by all tested ICAM-1-expressing cells, including epithelial, fibroblast and neuroblastoma cells, primary or established cell lines. Uptake was inhibited at $4{ }^{\circ} \mathrm{C}$ and in the presence of an inhibitor of the ICAM-1-associated pathway, rather than inhibitors of the clathrin or caveolar routes. We observed minimal transport of anti-ICAM to lysosomes, yet prominent and specific transcytosis across epithelial monolayers. Finally, we coupled a model cargo (the enzyme horseradish peroxidase (HRP)) to anti-ICAM and separated a 1:2 antibody:enzyme conjugate for non-multivalent ICAM-1 targeting. Similar to anti-ICAM, anti-ICAM-HRP was specifically internalized and transported across cells, which rendered intra- and trans-cellular enzyme activity. Therefore, non-multivalent ICAM-1 targeting also provides transport of cargoes into and across cells, representing a new alternative for future therapeutic applications via this route.
\end{abstract}

Keywords: drug targeting, monomeric vs. multimeric targeting; receptor-mediated endocytosis; transcytosis; antibody-enzyme conjugate; ICAM-1. 


\section{INTRODUCTION}

Uptake of therapeutic drugs by cells [1-3] and drug transport across cell linings that separate body compartments [4-7], are paramount events influencing the success of many therapeutic interventions. To induce these types of transport, many strategies target drugs or their carriers to cell-surface receptors [2, 3]. For this purpose, targeting molecules (antibodies, peptides, aptamers, etc.) are coupled either directly to a pharmaceutical agent (drug conjugates) or on the surface of drug-loaded carriers [1-3]. Upon their binding to cells, receptor-mediated endocytosis is triggered, which results in the formation of membraneenclosed vesicles that carry the drug conjugate or carrier within cells [1-3]. Following uptake, drug conjugates or carriers are typically trafficked to endo-lysosomal compartments, where pH- or enzymedependent cleavage may release the drug [1-3]. For drugs that cannot permeate the endo-lysosomal membrane or that are degraded in these compartments, additional strategies are required to enable cytosolic escape $[1,2]$. In other instances, receptor-mediated uptake results in transport across cellular barriers, such as the case of endothelial and epithelial linings that separate some body compartments [4, 5, $8,9]$.

The mechanisms that regulate receptor-mediated transport into or across cells include classical pathways, such as clathrin- and caveolae-dependent endocytosis and transcytosis, whose abundant biological information renders them readily exploitable in drug delivery [1-3]. In contrast, some clathrin- and caveolae-independent pathways have also been described, but their regulation and use in drug delivery is much less characterized $[2,3,10]$. An example is that of the transport pathway associated to intercellular adhesion molecule-1 (ICAM-1). ICAM-1 is a cell surface glycoprotein, whose expression on various cell types is up-regulated during most pathological conditions, thereby enabling drug targeting to diseased tissues [11].

Efficient uptake of therapeutics via ICAM-1 has been shown both in cell culture and in vivo [8, 9, 12-17]. Multivalent binding to ICAM-1 triggers uptake via Cell Adhesion Molecule (CAM)-mediated endocytosis, a non-classical pathway distinct from clathrin- and caveolae-mediated endocytosis, phagocytosis, and macropinocytosis [12,18]. Drug conjugates and carriers of various sizes, shapes, and chemistries have been shown to enter cell via this route upon multivalent binding to ICAM-1, providing 
therapeutic and/or imaging activity [19-23]. After uptake by cells, multivalent anti-ICAM conjugates and carriers were observed to traffic both to lysosomes and across cells, where they could deliver therapeutics $[8,9,19,24-26]$.

Contrary to multivalent binding of conjugates and carriers to ICAM-1, decade-old reports had indicated that binding of non-multivalent anti-ICAM molecules to ICAM-1 did not induce endocytic transport [12, 13]. However, using protocols more amenable than those previously available, we recently observed that anti-ICAM is endocytosed by endothelial cells [25]. Following uptake, a significant amount of anti-ICAM molecules recycled back to the plasmalemma, resulting in low endo-lysosomal accumulation, which had been misinterpreted as lack of uptake in previous works [25]. This finding may now provide an opportunity for direct conjugation of therapeutic or imaging agents to anti-ICAM molecules able to induce CAM-mediated transport. This holds significance because direct conjugation may offer a simpler formulation from a manufacturing perspective and may lead to distinct biodistribution, metabolism, clearance, etc., expanding the range of applications of ICAM-1 targeting.

The present study addressed several questions that remained unanswered: Does endocytosis of anti-ICAM molecules occur in cells other than endothelial, to enable delivery in other tissues? Do anti-ICAM molecules transcytose across cell linings, as previously observed for multivalent carriers? Are anti-ICAM molecules able to transport a drug cargo into and/or across cells?

\section{MATERIALS AND METHODS}

\section{Antibodies and reagents.}

Mouse anti-human ICAM-1 (anti-ICAM) was clone R6.5 (American Type Culture Collection; Manassas, VA, USA). Mouse IgG, anti-horseradish peroxidase (HRP), anti-human lysosomal-associated membrane protein 1 (LAMP-1), FITC- or Texas Red (TxR)-labeled secondary antibodies were from Jackson Immunoresearch (West Grove, PA, USA). HRP-conjugated antibodies and chemiluminescent detection reagents for Western blot were from General Electric Healthcare Bio-Sciences (Pittsburg, PA, USA). Lightning Link ${ }^{\circledR}$ HRP conjugation kit was from Innova Biosciences (Cambridge, UK). 
Tetramethylbenzidine (TMB0, substrate for HRP) and Pierce Iodogen iodination tubes were from Thermo Fisher Scientific (Rockford, IL, USA). Na ${ }^{125}$ I was from Perkin Elmer-Analytical Sciences (Wellesley, MA). All other reagents were from Sigma Aldrich (St. Louis, MO, USA).

\section{Cell culture.}

Human epithelial adenocarcinoma Caco-2 cells (a gift from Dr. Jerrold Turner, University of Chicago) were cultured at $37^{\circ} \mathrm{C}$ in Dulbecco's Modified Eagle Medium (GibcoBRL, Grand Island, NY, USA) supplemented with $10 \%$ fetal bovine serum and antibiotics. Other cells used were head and neck cancer A431 cells (ATCC, Manassas, VA), skin fibroblasts (a gift from Dr. Edward Schuchman, Mount Sinai School of Medicine), SH-SY5Y neuroblastoma (ATCC, Manassas, VA), and human umbilical vein endothelial cells (HUVECs), whose culture conditions have been reported elsewhere [15, 26]. Cells were seeded on gelatin-coated glass coverslips or Transwell ${ }^{\circledR}$ inserts (polyethylene terephthalate, $0.4-\mu \mathrm{m}$-pore size; BD Falcon, Franklin Lakes, NJ). The permeability of Caco-2 monolayers was assessed by measuring the transepithelial electrical resistance (TEER), using an EVOM ${ }^{\mathrm{TM}}$ volt-ohm meter and STX100 electrodes (World Precision Instruments, Sarasota, FL). Where specified, cells were pre-treated with 10 $\mathrm{ng} / \mathrm{ml}$ tumor necrosis factor-alpha (TNF $\alpha$; BD Biosciences, Franklin Lakes, NJ, USA) to mimic an inflammation status [11].

\section{ICAM-1 expression and cellular binding of anti-ICAM.}

Cells were incubated after fixation with $2 \%$ paraformaldehyde (to avoid uptake), or live, with 75-140 $\mathrm{pmol} / \mathrm{L}$ anti-ICAM or IgG for the indicated times and temperatures. Cells were washed, fixed and cellassociated antibody was immunostained using green FITC-labeled secondary antibody [25, 27]. Samples were analyzed using an Olympus IX81 microscope (Olympus Inc., Center Valley, PA), via phase contrast (to discern the cell borders) and fluorescence (to visualize antibodies). Micrographs were taken using an ORCA-ER camera (Hamamatsu, Bridgewater, NJ) and SlideBook ${ }^{\mathrm{TM}} 4.2$ software (Intelligent Imaging Innovations, Denver, CO). Images were analyzed using Image-Pro 6.3 (Media Cybernetics Inc., Bethesda, MD) to quantify the sum and mean fluorescence intensity, from which background fluorescence was subtracted [25, 27]. Measurements were done cell by cell for all micrographs, so that the 
level and homogeneity of binding of anti-ICAM on the surface of each cell in the population can be estimated, which relates to the level and homogeneity of ICAM-1 cell expression.

\section{Endocytosis of anti-ICAM.}

Cells were incubated at $37{ }^{\circ} \mathrm{C}$ with $75 \mathrm{pmol} / \mathrm{L}$ anti-ICAM or $\mathrm{IgG}$ for $30 \mathrm{~min}$ at $37{ }^{\circ} \mathrm{C}$ to allow binding (pulse), followed by washing and incubation at $37{ }^{\circ} \mathrm{C}$ up to $5 \mathrm{~h}$ (chase) to allow uptake. Uptake at $4{ }^{\circ} \mathrm{C}$ or in the presence of $3 \mathrm{mM}$ amiloride (to inhibit CAM endocytosis), $50 \mu \mathrm{mol} / \mathrm{L}$ monodansylcadaverine (MDC; to inhibit clathrin pits), or $1 \mu \mathrm{g} / \mathrm{ml}$ filipin (to inhibit caveoli) served to evaluate the pathway [12]. Cells were fixed and antibodies bound on cells were immunostained in red using TxR-goat secondary antibody. Cells were then permeabilized and incubated with FITC-goat secondary antibody, to label all (bound and internalized) antibodies in green. Hence, the cell-surface bound fraction was double-labeled in green and red (yellow), while internalized counterparts were single-labeled in green [25, 27]. Samples were analyzed by fluorescence microscopy and quantified to obtain the internalized fluorescence as an absolute value or a percentage compared to the total cell-associated fluorescence [25, 27].

\section{Lysosomal trafficking of anti-ICAM.}

Cells were incubated at $37^{\circ} \mathrm{C}$ with $140 \mathrm{pmol} / \mathrm{L}$ FITC-labeled anti-ICAM or IgG using the pulse-chase protocol described above. Incubations were conducted in the absence vs. presence of $300 \mu \mathrm{mol} / \mathrm{L}$ chloroquine, to inactivate lysosomal hydrolases. Cells were fixed, permeabilized, and LAMP-1-positive lysosomes were immunostained with a Texas Red (TxR)-labeled antibody. Co-localization of green antiICAM with red lysosomes was quantified by fluorescence microscopy, as described [25]. Degradation of anti-ICAM was estimated by comparing its total fluorescence at any given time to that of the initial 30 $\min$ pulse [25].

\section{Trancellular transport of anti-ICAM.}

${ }^{125} \mathrm{I}$-anti-ICAM or control ${ }^{125} \mathrm{I}-\mathrm{IgG}(70 \mathrm{pmol} / \mathrm{L} ; 56 \mathrm{nCi} / \mathrm{ml})$ were added to the chamber above cell monolayers grown on Transwell@ filters, verified to be confluent (see Cell culture section). After incubation at $37^{\circ} \mathrm{C}$ for the indicated times, the radioisotope content in the chamber above the cells (nonbound antibodies), the chamber below the cell (transported antibodies), and the cell fraction (cell- 
associated antibodies) were measured using a gamma counter. Results were corrected by subtracting the level of free ${ }^{125}$ Iodine of each fraction, measured by trichloroacetic acid (TCA) precipitation [9]. The number of antibody molecules associated with and transported across cells, the percentage of molecules transported from this total, and the apparent permeability coefficient $\left(\mathrm{P}_{\mathrm{app}}\right)$ were determined as follows:

Antibody molecules transported $/ \mathrm{mm}^{2}=\left[\left(\left(\mathrm{CPM}_{\text {basolateral }} /\right.\right.\right.$ antibody Specific Activity $\left.\left.) / \mathrm{MW}\right) \times \mathrm{N}_{\mathrm{avo}}\right] / \mathrm{mm}^{2}$

$\%$ Antibody transported $=100 \times\left[\mathrm{CPM}_{\text {basolateral }} /\left(\mathrm{CPM}_{\text {basolateral }}+\mathrm{CPM}_{\text {cell fraction }}\right)\right]$

$$
\mathrm{P}_{\text {app }}(\mathrm{cm} / \mathrm{s})=\left(\mathrm{CPM}_{\text {basolateral }} \times \mathrm{Vol}\right) /\left(\mathrm{A} \times \mathrm{t} \times \mathrm{CPM}_{\text {added }}\right),
$$

where CPM is the ${ }^{125}$ Iodine counts-per-minute in the upper chamber $\left(\mathrm{CPM}_{\text {added }}\right)$, the cell fraction $\left(\mathrm{CPM}_{\text {cell }}\right.$ fraction $)$, or the lower chamber $\left(\mathrm{CPM}_{\text {basolateral }}\right)$, the antibody Specific Activity is the $\mathrm{CPM} / \mathrm{g}$ of protein, MW is molecular weight $(\mathrm{g} / \mathrm{mol}), \mathrm{N}_{\text {avo }}$ is Avogadro's number, $\mathrm{A}$ is the surface area of the filter membrane $\left(\mathrm{cm}^{2}\right), \mathrm{mm}^{2}$ also refer to this area, Vol is volume of medium in the upper chamber $(\mathrm{ml})$, and $\mathrm{t}$ is time of incubation (s) [9].

${ }^{125} \mathrm{I}$-anti-ICAM transport was compared in the absence vs. presence of $20 \mu \mathrm{mol} / \mathrm{L} 5$-(N-ethyl-N-isopropyl) amiloride (EIPA), which inhibits CAM-mediated transport [8,9]. The status of the monolayer was assessed by measuring the TEER and examining paracellular leakage of ${ }^{125}$ I-albumin [9]. Treatment of cells with $5 \mathrm{mmol} / \mathrm{L} \mathrm{H}_{2} \mathrm{O}_{2}$, known to disrupt cell junctions, served as a control [9].

\section{Preparation and characterization of antibody-enzyme conjugates.}

Following the manufacturer's instructions for the Lightning Link ${ }^{\circledR}$ HRP Conjugation Kit, anti-ICAM or IgG $(13 \mu \mathrm{mol} / \mathrm{L})$ were incubated with LL-Modifier reagent ${ }^{\circledR}(1 \mu \mathrm{l} / \mu \mathrm{l}$ of antibody $)$ and $\mathrm{HRP}(21 \mu \mathrm{mol} / \mathrm{L})$ for $3 \mathrm{~h}$ at room temperature before adding LL-Quencher reagent ${ }^{\circledR}$. This reaction covalently links primary amine groups of the antibody to lysine residues of HRP, to yield conjugates with a 1:2 antibody-toenzyme molar ratio. Molecular weight and presence of antibody-enzyme conjugates were examined using SDS-PAGE under denaturing, non-reducing conditions followed by Coomassie blue staining and Western blotting. Conjugates or unconjugated counterparts were also separated using Asymmetrical Flow FieldFlow Fractionation (AF4) with Multi-Angle Light Scattering (MALS) and Quasi-Elastic Light Scattering (QELS) detection (Wyatt Technology, Santa Barbara, CA). An Agilent UV detector (280 nm) and a 
Wyatt Optilab T-rEX differential refractive index (RI) detector (Wyatt Technology, Santa Barbara, CA, USA) monitored sample elution. A $350 \mu \mathrm{m}$ thickness spacer was used to house a $10 \mathrm{kDa}$ molar mass cutoff regenerated cellulose membrane (Microdyn, Raleigh, NC) for the separation. Flow was controlled using Eclipse software (Wyatt Technology). The AF4 carrier liquid was $10 \mathrm{mmol} / \mathrm{L}$ phosphate buffered saline at $\mathrm{pH}$ 7.4. Samples were injected while focusing at $2.2 \mathrm{~mL} / \mathrm{min}$ for $2 \mathrm{~min}$, followed by a second focusing step of $2.2 \mathrm{~mL} / \mathrm{min}$ for $2 \mathrm{~min}$. The crossflow was kept constant at $1.4 \mathrm{~mL} / \mathrm{min}$ for $24 \mathrm{~min}$ while eluting the injected samples at $0.6 \mathrm{~mL} / \mathrm{min}$. UV, RI, and MALS data were obtained followed by conversion into molar mass, particle size, and size distributions using ASTRA ${ }^{\circledR}$ 6.1.2.84 software. MALS intensity $(690 \mathrm{~nm})$ was measured at 15 angles and data collected at $1 \mathrm{~s}$ intervals and QELS data at $5 \mathrm{~s}$ intervals. The QELS data were fitted to a single-mode exponential decay model to measure the translational diffusion coefficient with the hydrodynamic radii of the particles calculated via StokesEinstein equations. The apparent molar mass was calculated from the collected UV, RI, and MALS data using Zimm formalism with molar extinction coefficient of $1.4 \mathrm{~mL} / \mathrm{g} \cdot \mathrm{cm}$, which is that of antibodies in aqueous solutions, and a specific refractive index value $(\mathrm{dn} / \mathrm{dc})$ of $0.18 \mathrm{~mL} / \mathrm{g}$. The eluted conjugated species were separated into two major fractions ( $233 \mathrm{kDa}$ and $686 \mathrm{kDa}$; see Results).

\section{Cellular binding of anti-ICAM-enzyme conjugates.}

Cells were fixed and incubated for $1 \mathrm{~h}$ with either anti-ICAM-HRP conjugates or control IgG-HRP conjugates (75 pmol/L antibody and $150 \mathrm{pmol} / \mathrm{L}$ HRP) vs. non-conjugated HRP (150 pmol/L) or antiICAM (75 pmol/L). Incubation with anti-ICAM-HRP conjugates in the presence of anti-ICAM competitor or IgG served as controls. Cell-bound antibody was immunostained using green, while cellbound HRP was immunostained in red. Binding was assessed by micrograph quantification of the mean green or red fluorescence for anti-ICAM or HRP, and their percentage of co-localization [27].

We also measured HRP activity bound on cells by using TMB substrate, followed by quenching with 2 $\mathrm{mol} / \mathrm{L}$ sulfuric acid. Absorbance at $450 \mathrm{~nm}$ was quantified by spectrophotometry, and HRP concentration was then derived from standard curves correlating absorbance and HRP activity. 


\section{Endocytosis of anti-ICAM-enzyme conjugates.}

Control or TNF $\alpha$-activated cells were incubated with anti-ICAM-HRP conjugates (separated or nonseparated fractions) or IgG-HRP conjugates (75 pmol/L antibody and 150 pmol/L HRP) for 30 min at 37 ${ }^{\circ} \mathrm{C}$ (pulse), followed by washing and incubation at $37{ }^{\circ} \mathrm{C}$ (chase). Incubations were performed in the absence vs. presence of $3 \mathrm{mmol} / \mathrm{L}$ amiloride, to infer CAM-mediated uptake. Cells were washed, fixed, and the antibody counterpart was immunostained in red. Cells were then permeabilized and all (bound + internalized) antibody molecules were immunostained in green. In parallel, we immunodetected bound vs. internalized HRP counterpart. In both cases, the cell-surface bound fraction was double-labeled in green and red (yellow), while internalized counterparts were single-labeled in green. Samples were analyzed by fluorescence microscopy to quantify internalized fluorescence, as an absolute value or a percentage of the total cell-associated amount $[25,27]$.

Internalized enzyme activity was also evaluated by incubating cells with anti-ICAM-HRP conjugates, IgG-HRP conjugates, or non-conjugated anti-ICAM or HRP in the absence vs. presence of $3 \mathrm{mmol} / \mathrm{L}$ amiloride. Cells were washed and tested for HRP activity without permeabilization, which would render

activity bound on the cell surface. In parallel, cells were permeabilized to obtain the total surface-bound + internalized activity. HRP activity was assessed as described above.

\section{Transcellular transport of anti-ICAM-enzyme conjugates.}

Anti-ICAM-HRP conjugates (separated or non-separated fractions) vs. IgG-HRP, unconjugated HRP, or unconjugated anti-ICAM (70 pmol/L) were added to the apical Transwell ${ }^{\circledR}$ chamber above the cells and incubated at $37{ }^{\circ} \mathrm{C}$ for the indicated times. Additional controls consisted of incubating anti-ICAM-HRP conjugates in the presence of anti-ICAM competitor vs. IgG, or in the presence of $20 \mu \mathrm{mol} / \mathrm{L}$ EIPA to inhibit the CAM pathway. The paracellular transport was evaluated by monitoring the TEER. The apical, cell, and basolateral fractions were collected and measured for HRP activity as described above. The percent of transport was calculated from the total activity found in the cell fraction + basolateral fraction. 


\section{Statistical Analysis}

Data were collected as mean \pm standard error of the mean (S.E.M). For each experimental condition analyzed by fluorescence microscopy, the number of independent samples was $\geq 4$. For enzyme activity assays, the number of independent samples was $\geq 6$. Significance was determined using the Student's unpaired $t$-test, assuming a p-value of 0.05 .

\section{RESULTS}

\section{Binding and endocytosis of anti-ICAM by non-endothelial cells.}

Endocytosis of anti-ICAM molecules has been recently demonstrated using primary endothelial cells [25]. Here, we examined if this is also the case for non-endothelial, epithelial colorectal adenocarcinoma Caco2 cells, an established cell line. Fluorescence immunostaining showed that anti-ICAM specifically bound to and was internalized by both quiescent and TNF $\alpha$-activated Caco- 2 cells in a time-dependent manner: e.g., binding was 7 -fold over IgG by $30 \mathrm{~min}$, and $50 \%$ of all cell-associated anti-ICAM was internalized by $1 \mathrm{~h}$, while IgG uptake was not detectable (Supplementary Figures 1 and 2, and Figure 1A, B). Uptake seemed to decrease by $5 \mathrm{~h}$ (Figure 1B and Supplementary Figure 2), but this was not due to degradation as the total cell-associated antibody did not decay (Supplementary Figure 3). Uptake was inhibited at $4{ }^{\circ} \mathrm{C}$ $\left(16 \%\right.$ of $37{ }^{\circ} \mathrm{C}$ ) and in the presence of amiloride (49\% of control), a drug which inhibits the $\mathrm{Na}^{+} / \mathrm{H}^{+}$ exchanger involved in the CAM pathway [12,18], but not by filipin or MDC (88\% and 99\% of control), which affect caveoli and clathrin pits respectively $[12,18]$ (Figure 1C and Supplementary Figure 4). Endocytosis of anti-ICAM was also confirmed in squamous carcinoma A431 cells, neuroblastoma SHSY5Y, and primary skin fibroblasts, where the level of binding and total uptake correlated well with their respective levels ofICAM-1 expression (compare lower binding, total uptake and expression in A431 and SH-SY5Y cells vs. higher binding, total uptake and expression in fibroblasts; Supplementary Figures 5, 6 and 7). Therefore, endocytosis of anti-ICAM molecules also occurs in non-endothelial cells. 

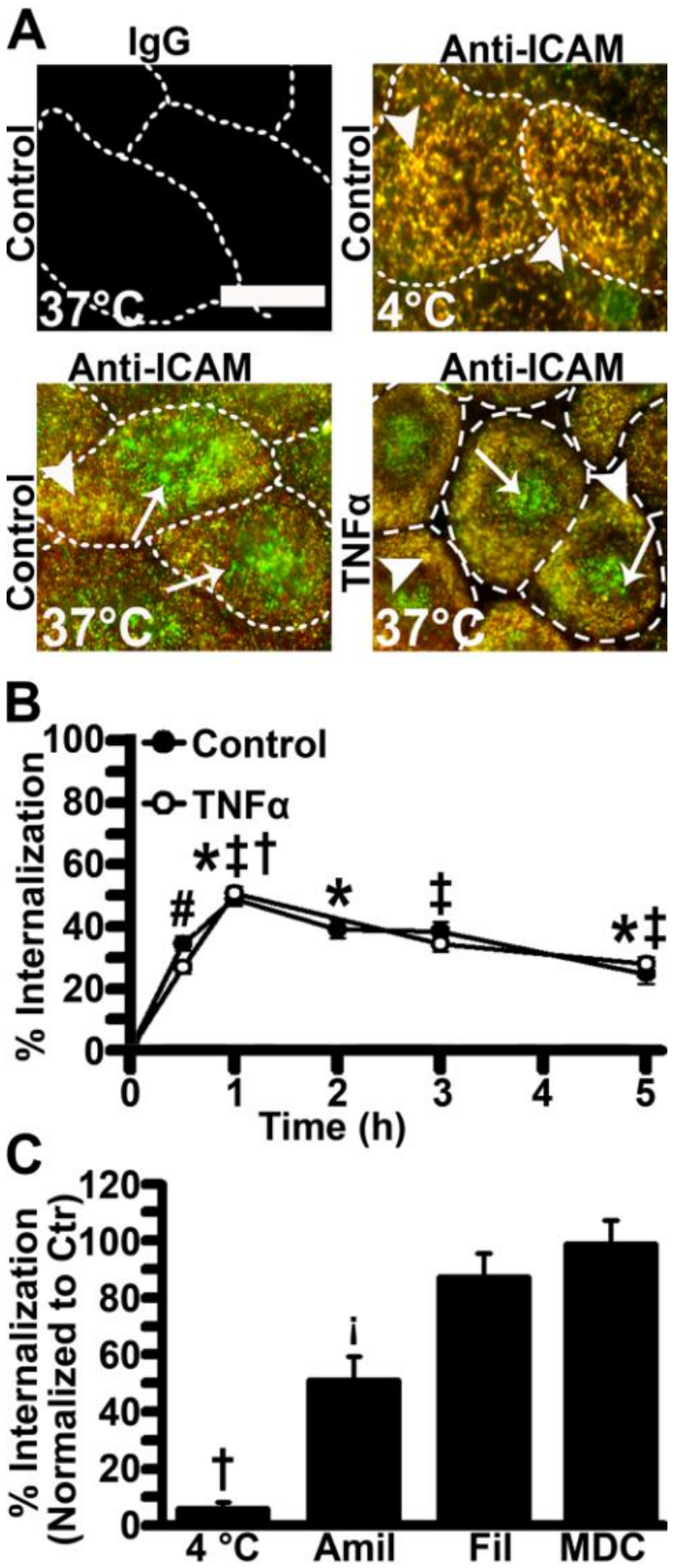

Figure 1. Uptake of anti-ICAM by Caco-2 cells. (A) AntiICAM or control $\mathrm{IgG}$ were incubated for $30 \mathrm{~min}$ at $37^{\circ} \mathrm{C}$ or 4 ${ }^{\circ} \mathrm{C}$ with control vs. TNF $\alpha$-activated Caco- 2 cells. Non-bound antibody was then removed and cells were incubated for additional 30 min to allow endocytosis of pre-bound antibody. Cells were fixed and incubated with TxR-labeled secondary antibody, accessible only to surface-bound counterparts. Cells were then permeabilized to label total cell-surface + internalized antibody with FITC-labeled secondary antibody. Hence, cell-surface antibody appears yellow (green + red; arrowheads) vs. green internalized counterparts (arrows). Scale bar $=10 \mu \mathrm{m}$. Dashed lines mark the cell borders, observed by phase contrast. (B) The percentage of anti-ICAM internalization at $37{ }^{\circ} \mathrm{C}$ and different time points was expressed as the fraction of internalized antibody vs. total (surface-bound + internalized) antibody. (C) The percentage of anti-ICAM uptake (1 h, 37 ${ }^{\circ} \mathrm{C}$ ) was assessed in absence (control; Ctr) vs. presence of amiloride (Amil), filipin (Fil), or monodansylcadaverine (MDC), and normalized to control cells. Data are Mean \pm S.E.M. * Compares each time point to the preceding one, for control cells; $\$$ compares each time point to the preceding one, for TNF $\alpha$-activated cells; \# compares control vs. TNF $\alpha$ at respective time points; $\uparrow$ compares uptake at $37{ }^{\circ} \mathrm{C}$ vs. 4 ${ }^{\circ} \mathrm{C} ; ;$ compares inhibitor-treated vs. control cells $(\mathrm{p}<0.05$, Student's t test). 


\section{Lysosomal trafficking of anti-ICAM in non-endothelial cells.}

We next examined lysosomal transport of anti-ICAM, which in endothelial cells was markedly low compared to anti-ICAM coated onto nanocarriers [25]. We observed that anti-ICAM also exhibited low colocalization with lysosomal LAMP-1 in Caco-2 cells: $14 \%$ and 27\% colocalization at $1 \mathrm{~h}$ and $5 \mathrm{~h}$ (Figure 2A, B). Since anti-ICAM degradation within lysosomes could have impaired our ability to observe colocalization, we repeated these experiments in the presence of chloroquine, a weak base that impairs lysosomal degradation. In the presence of chloroquine, lysosomal colocalization of anti-ICAM decreased to $\sim 16 \%$ at $5 \mathrm{~h}$, showing that the drug indeed impacts this compartment (Figure 2B). Yet, total immunodetectable anti-ICAM did not vary with time (Supplementary Figure 3), with only $11 \%$ signal decay in control cell medium and 2\% decay in chloroquine by $5 \mathrm{~h}$ (Figure 2C). This result confirms minor lysosomal trafficking and degradation, as for endothelial cells [25].

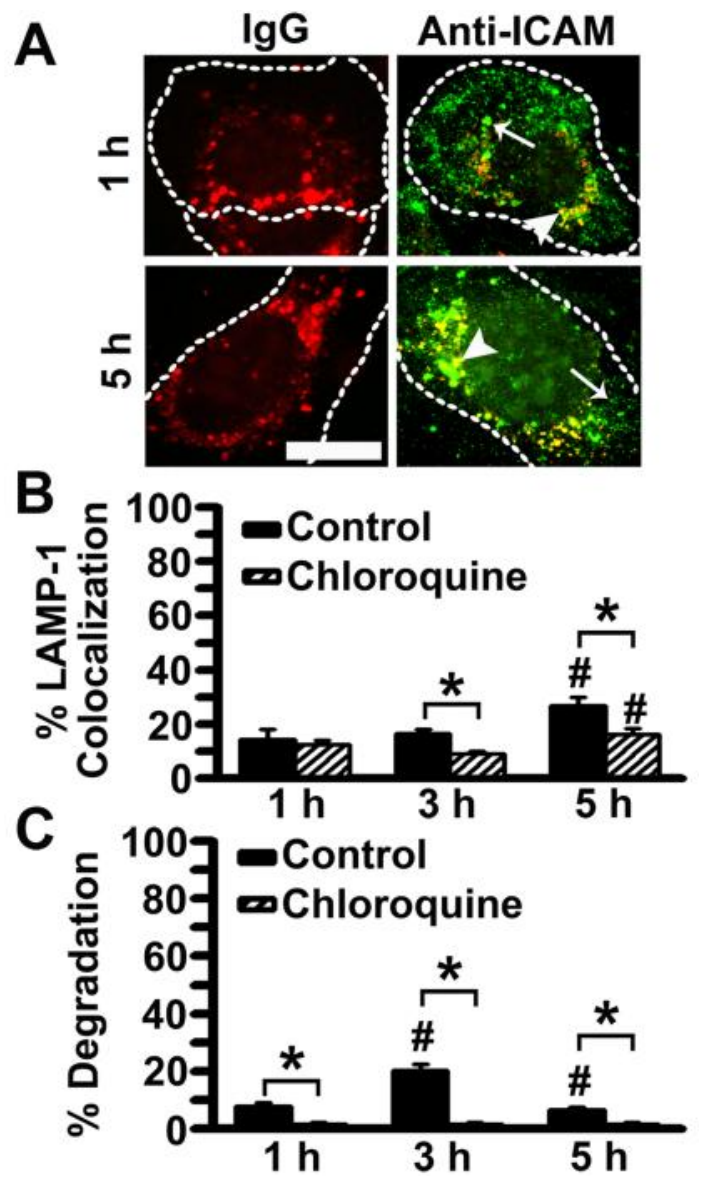

Figure 2. Lysosomal trafficking of anti-ICAM in Caco-2 cells. (A) Caco- 2 cells cultured on coverslips were incubated with FITClabeled anti-ICAM or IgG for $30 \mathrm{~min}$ at $37^{\circ} \mathrm{C}$ (binding pulse), followed by washing and incubation at $37{ }^{\circ} \mathrm{C}$ (chase). As a control for degradation, cells were additionally incubated with chloroquine. Cells were fixed and permeabilized, and LAMP-1-positive lysosomes were immunostained with TxR-anti-LAMP-1. Antibodies that colocalize with lysosomes appear double-labeled with TxR and FITC (yellow; arrowheads), while non-colocalized antibodies are single-labeled in green FITC (arrows). Scale bar $=$ $10 \mu \mathrm{m}$. Dashed lines mark the cell borders, observed by phase contrast. (B) Colocalization of green antibody with red-labeled lysosomes was calculated from micrographs. (C) Degradation of FITC-anti-ICAM was estimated by comparing total fluorescence remaining over time to cell-associated fluorescence after the first 30 min incubation. Data are Mean \pm S.E.M. * Compares presence vs. absence of chloroquine; \# compares each time point to the preceding one $(\mathrm{p}<0.05$, Student's $t$ test $)$. 


\section{Transport of anti-ICAM across non-endothelial (epithelial) cell monolayers.}

Transport across cell barriers has been reported for multivalent anti-ICAM carriers using endothelial and epithelial models [8, 9]. Hence, we examined if anti-ICAM molecules can also undergo this route. We used Caco-2 monolayers grown on Transwell ${ }^{\circledR}$ inserts after verifying their confluency by presence of tight junctions and TEER (Supplementary Figure 8A). Immunofluorescence and radioisotope tracing showed that anti-ICAM bound specifically to cell monolayers, e.g., 12-fold over IgG (Supplementary Figure 8B, C). Specific, time dependent transport to the basolateral chamber under the cells was observed: e.g., $3 \times 10^{9}$ anti-ICAM molecules were transported per $\mathrm{mm}^{2}$ of epithelium by $24 \mathrm{~h}(15$-fold over IgG;

Figure 3A). This represented $\sim 80 \%$ of all anti-ICAM initially associated to cells (cell+basolateral fractions), a 4-fold greater apparent permeability coefficient ( $\left.\mathrm{P}_{\text {app }}\right)$ vs. $\mathrm{IgG}$ (Supplementary Figure 9A, B).
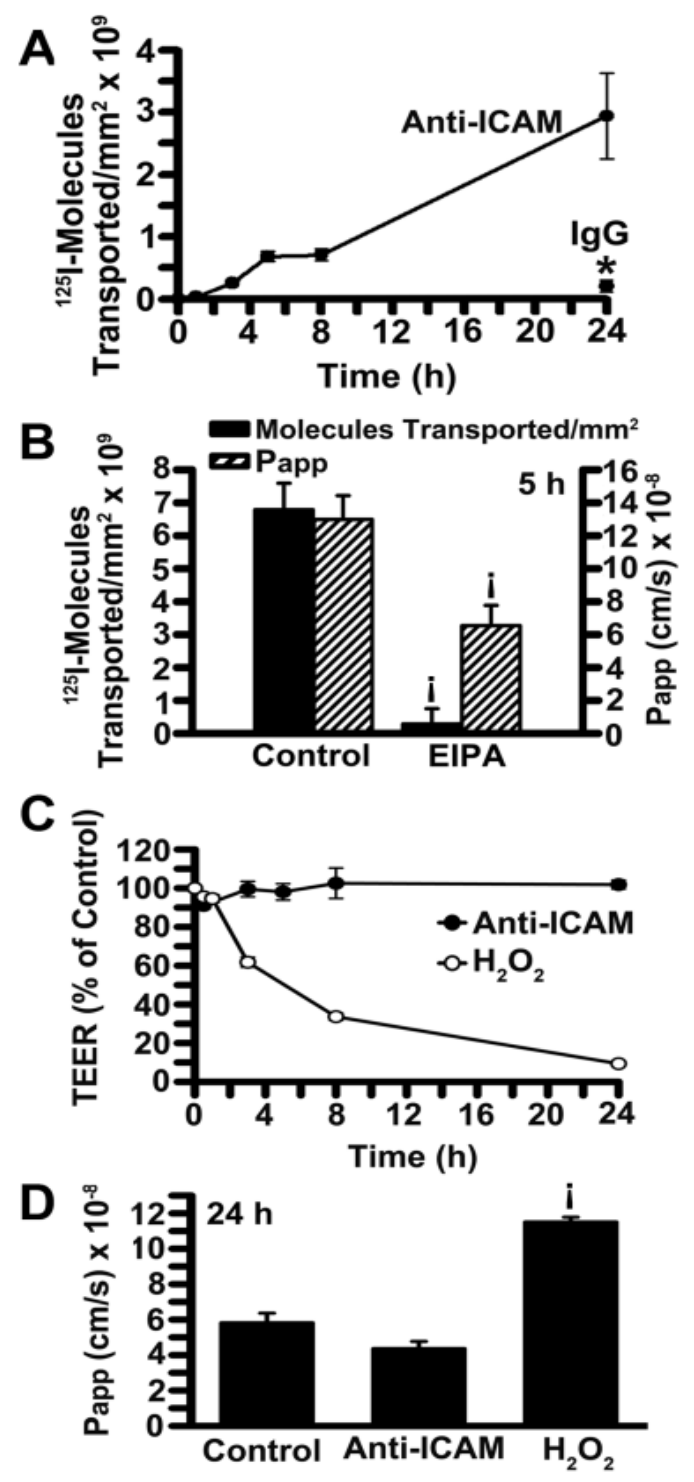

Anti-ICAM transport was inhibited by an amiloride derivative (50-95\% inhibition by $5 \mathrm{~h}$; Figure 3B) and did not cause any changes to the monolayer permeability ( 100\% of control TEER), nor it led to increased leakage, in contrast with $\mathrm{H}_{2} \mathrm{O}_{2}$ which opens the cell junctions (Figure 3C, D).

Figure 3. Transepithelial transport of anti-ICAM across Caco-2 monolayers. ${ }^{125} \mathrm{I}$-anti-ICAM or ${ }^{125} \mathrm{I}$-IgG were added above Caco-2 monolayers cultured on Transwell inserts, to permit transport to the basolateral chamber. (A) Basolateral ${ }^{125}$ I was measured to calculate the amount of antibodies transported per $\mathrm{mm}^{2}$ (see Methods). IgG is shown for $24 \mathrm{~h}$. (B) Transepithelial transport of ${ }^{125} \mathrm{I}$-anti-ICAM in the absence or presence of EIPA $(5 \mathrm{~h})$, shown as antibody molecules transported per $\mathrm{mm}^{2}$ and rate of transport $\left(\mathrm{P}_{\text {app }}\right)$. (C) TEER was measured during transport of ${ }^{125}$ I-anti-ICAM across Caco-2 cells and compared to $\mathrm{H}_{2} \mathrm{O}_{2}$ treatment, which causes intercellular junction opening. TEER is expressed as a percentage of the values measured for untreated, control cells. (D) Paracellular protein leakage, measured as the $\mathrm{P}_{\text {app }}$ of ${ }^{125} \mathrm{I}-$ albumin crossing the cell monolayer in the absence or presence of $\mathrm{H}_{2} \mathrm{O}_{2}$ or anti-ICAM. Data are Mean \pm S.E.M. * Compares anti-ICAM vs. IgG; $;$ compares against control cells $(\mathrm{p}<0.05$, Student's $t$ test). 


\section{Conjugation of a model enzyme to anti-ICAM.}

Since anti-ICAM molecules were observed to enter and cross cells, we explored if anti-ICAM could similarly mobilize a cargo. While cargo delivery into and across cells has been documented for antiICAM conjugates and nanocarriers displaying multiple anti-ICAM copies [12-17], it has never been shown for anti-ICAM molecules. We conjugated anti-ICAM to a model cargo, HRP, using a commercial kit for conjugation at 1:2 antibody-to-enzyme molar ratio. We first verified the conjugate by SDS-PAGE followed by Coomassie blue staining and Western blotting (Figure 4A). Coomassie staining revealed the expected $\sim 150 \mathrm{kDa}$ band (Lane 2) and $\sim 40 \mathrm{kDa}$ band (Lane 3) for unconjugated anti-ICAM and HRP, and a predominant $\sim 230 \mathrm{kDa}$ band for the conjugate mixture (arrow in Lane 1), expected for a conjugate carrying 2 HRP molecules per anti-ICAM molecule. Both antibody and HRP components were immunodetectable on this band (arrows in Lanes 4 and 7), similar to unconjugated anti-ICAM and unconjugated HRP (Lanes 5-6 and 8-9). Apart from this predominant band, faint bands of $\sim 150 \mathrm{kDa}$ and $\sim 40 \mathrm{kDa}$ were present in the conjugate mixture (Lane 1), positive for either anti-ICAM or HRP, but not both (Lanes 4 and 7). Hence, these are unconjugated traces. In addition, two bands above $230 \mathrm{kDa}$ (Lane 1) were positive for anti-ICAM and HRP (Lanes 4 and 7), suggesting the presence of larger conjugates. However, the Coomassie blue intensity of these bands was significantly lower, indicating that they represent a minor fraction vs. the predominant $\sim 230 \mathrm{kDa}$ conjugate.

We then used AF4 coupled to MALS, RI, and UV absorbance detectors to characterize the conjugate mixture [29]. The representation of the differential weight fraction vs. molecular weight in Figure 4B shows that unconjugated HRP and anti-ICAM have monodisperse peaks with average molecular weights of $43 \mathrm{kDa}$ and $155 \mathrm{kDa}$, respectively. The anti-ICAM-HRP conjugate mixture contained several species. A minor ( $10 \%$ of the population) peak averaging $196 \mathrm{kDa}$ was found, equivalent to a mixture of 1:1 antibody:enzyme conjugate and unconjugated anti-ICAM. Unconjugated HRP was not detected. The main peak ( $40 \%$ of the population) had molecular weight between $190-340 \mathrm{kDa}$, which corresponds to antibody-to-enzyme molar ratios of 1:1 to 1:4, all with a single anti-ICAM molecule. The average molecular weight of this population was $233 \mathrm{kDa}$, corresponding to a 1:2 antibody:enzyme conjugate, as seen by SDS-PAGE. Another $40 \%$ peak with average molecular weight of $686 \mathrm{kDa}$ was present, equivalent to large conjugates and/or aggregates. Since this population is likely to contain species bearing more than one antibody molecule (similar to multivalent anti-ICAM carriers and opposite to the $233 \mathrm{kDa}$ 
population), we conducted experiments comparing the AF4- separated $233 \mathrm{kDa} v \mathrm{vs} 686 \mathrm{kDa}$ fractions vs. the unseparated conjugate mixture.

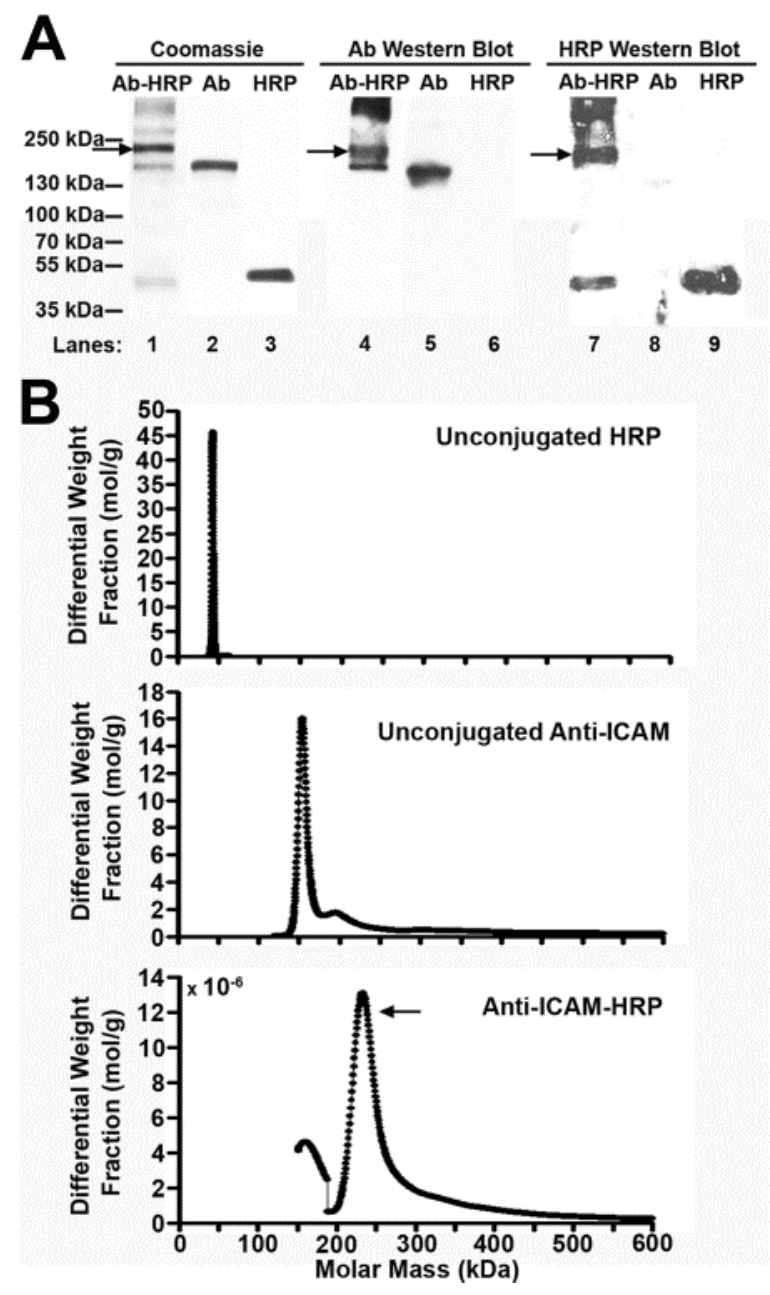

Figure 4. Characterization of anti-ICAM-HRP conjugates. Horseradish peroxidase (HRP) was conjugated to anti-ICAM antibody $(\mathrm{Ab})$ to yield a theoretical antibody-to-enzyme molar ratio of 1:2. (A) The anti-ICAM-HRP conjugate mixture vs. unconjugated anti-ICAM or HRP were separated by denaturing, non-reducing SDS-PAGE. Left: Coomassie blue staining of protein bands. Right: Western blot using either goat anti-mouse IgG-HRP to visualize anti-ICAM (Lanes 4-6), or rabbit antiHRP followed by goat anti-rabbit IgG-HRP to visualize HRP (Lanes 7-9). Arrows designate a predominant $\sim 230 \mathrm{kDa}$ conjugate band. (B) HRP, anti-ICAM, and anti-ICAM-HRP fractionated using AF4 connected with MALS, QELS, UV and RI detectors, to characterize the differential weight fraction $(\mathrm{mol} / \mathrm{g})$ of eluted samples as a function of molar mass $(\mathrm{kDa})$. A predominant peak with an average molar mass of $233 \mathrm{kDa}$ is observed for anti-ICAM-HRP (arrow).

\section{Specific binding and uptake of active anti-ICAM-enzyme conjugates by cells.}

We validated that anti-ICAM-HRP conjugates bind specifically to cells through the antibody counterpart, rendering HRP-specific activity. Using fixed Caco-2 cells, we tested the conjugate mixture since uptake was not to be traced yet. Both the anti-ICAM and HRP counterparts of the conjugate were visibly bound to cells: $5.8 \times 10^{7}$ and $9.5 \times 10^{7}$ fluorescence A.U., respectively (Figure $5 \mathrm{~A}, \mathrm{~B}$ ) with $>95 \%$ signal colocalization (Supplementary Figure 10). This was comparable to binding of anti-ICAM (1.3-fold the level of anti-ICAM-HRP), and specific over HRP (<10\% the level of anti-ICAM-HRP) and control IgGHRP conjugates ( $<1 \%$ the level of anti-ICAM-HRP; Figure 5A, B). Unconjugated anti-ICAM did not display an HRP signal and unconjugated HRP did not display anti-ICAM signal (<10\% compared to antiICAM-HRP; Figure 5A, B), resulting in no colocalization ( $<2 \%$; Supplementary Figure 10). Binding of 
anti-ICAM-HRP conjugates to cells was reduced by the presence of competing anti-ICAM molecules in the cell media (47\% decreased binding) but not $\operatorname{IgG}$ (3\% decreased binding; Figure 5B and Supplementary Figure 11). Further validating specificity (Supplementary Figure 12A), binding of antiICAM-HRP conjugates was almost undetectable in non-activated vs. high in TNF $\alpha$-activated endothelial cells (67-fold greater in the latter), as expected due to a reported 50-100 fold greater ICAM-1 expression in TNF $\alpha$-activated vs. non-activated cells [30].

In addition, anti-ICAM-HRP rendered measurable cell-bound HRP activity: $127 \mathrm{pmol} / \mathrm{L}$ by $1 \mathrm{~h}$, as opposed to IgG-HRP or HRP that had $1 \%$ and $3 \%$ the activity of anti-ICAM-HRP given their lack of

A
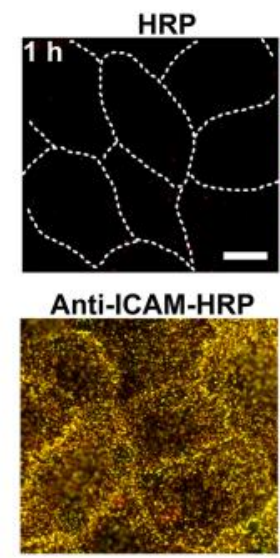

B
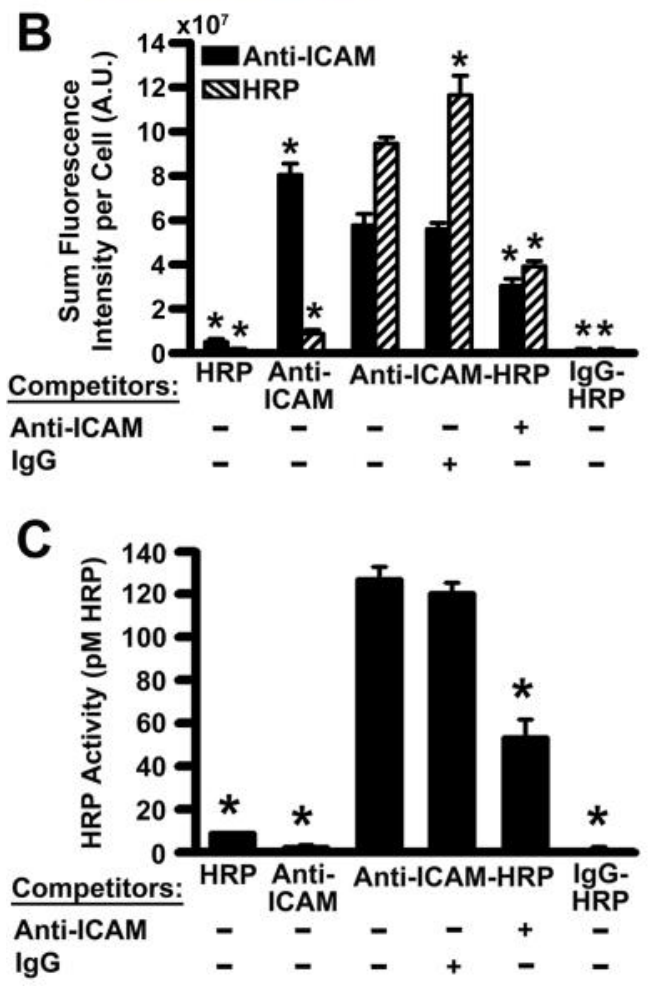

binding (Figure 5C). Although anti-ICAM molecules bound to cells, they did not render HRP activity (7\% the activity of antiICAM-HRP), as expected. Anti-ICAM competitor diminished the cell-bound activity of anti-ICAM-HRP conjugates $(42 \%$ of control), in contrast to IgG (95\% of control). Hence, antiICAM-HRP conjugates bind specifically to ICAM-1 on cells while preserving the activity of the enzyme cargo.

Figure 5. Specific binding and activity of anti-ICAM-HRP conjugates bound to Caco-2 cells. Fixed Caco-2 cells were incubated for $1 \mathrm{~h}$ at room temperature with non-conjugated HRP or anti-ICAM vs. anti-ICAM-HRP conjugates or control IgG-HRP conjugates. Incubations were performed either in control cell medium or medium containing anti-ICAM, to serve as a binding competitor, or non-specific IgG control. (A) Anti-ICAM was immunostained with FITC-labeled goat anti-mouse IgG (green), while HRP was immunostained with rabbit anti-HRP and TxR goat anti-rabbit IgG (red). Colocalization of anti-ICAM with HRP appears in yellow (green + red). Scale bar $=10 \mu \mathrm{m}$. Dashed lines mark the cell borders, observed by phase contrast. (B) The green FITC fluorescence was used to quantify binding of the anti-ICAM counterpart and the red TxR fluorescence was used to quantify binding of the HRP counterpart. (C) Cells were washed to remove the non-bound counterparts and HRP substrate was added to cells to measure HRP activity (pmol/L HRP). Data are Mean \pm S.E.M. * Compares any condition against anti-ICAM-HRP in the absence of competitors ( $\mathrm{p}<0.05$, Student's $t$ test). 
Then, using live cells we determined whether non-multivalent anti-ICAM molecules (vs. multivalent formulations bearing multiple copies of anti-ICAM) can mobilize cargo into cells. First, the conjugate mixture was internalized by cells as expected, and the total uptake correlated with the expression level of ICAM-1: 60 vs. 12,206 fluorescence A.U. for control vs. activated endothelial cells, which are known to express low vs. high ICAM-1 levels (Supplementary Figure 12B). We then used AF4-seperated fractions of the conjugates: the peak averaging $233 \mathrm{kDa}$ containing species with only one antibody molecule (nonmultivalent anti-ICAM species) vs. the peak averaging $686 \mathrm{kDa}$ containing larger conjugates or aggregates (multivalent anti-ICAM species). As for the mixture, internalization was also found for separated conjugates (mixture, $233 \mathrm{kDa}$, and $686 \mathrm{kDa}$ ) irrespective of tracing of the anti-ICAM or HRP counterparts: uptake ranged between $27-54 \%$ of the all cell associated conjugates (Figure 6A). The 233 $\mathrm{kDa}$ conjugate was internalized to an equivalent degree as unseparated conjugates (100\% of the uptake observed for the mixture when tracing anti-ICAM and 91\% when tracing HRP). Uptake of the $686 \mathrm{kDa}$ conjugate was slightly lower (87\% and 69\% compared to the unseparated mixture when tracing antiICAM or HRP), expected due to its larger size. HRP activity was also measured, without cell permeabilization (to measure cell-surface bound activity) vs. with permeabilization (to measure surfacebound + internalized HRP), so that the difference renders the internalized enzyme activity. As expected, total anti-ICAM-HRP conjugate activity measured after permeabilization was 3.7-fold greater than in the absence of permeabilization (surface-activity); hence, $68 \%$ of the total HRP activity provided by antiICAM-HRP was located within cells (Figure 6B, C). In contrast, minimal enzyme activity was detected in cells incubated with unconjugated HRP or anti-ICAM molecules, whether or not the cells were permeabilized (e.g., 10-30-fold lower than for anti-ICAM-HRP; Figure 6B). Looking at the internalized activity alone (permeabilized - non-permeabilized cells), this was $>9$-fold greater for cells incubated with anti-ICAM conjugates vs. unconjugated HRP or anti-ICAM (Supplementary Figure 13). This demonstrates that internalized enzyme activity is specifically delivered by anti-ICAM conjugates. In fact, inhibiting CAM endocytosis using amiloride resulted in a marked reduction in the internalized HRP activity of the conjugate (25\% of control; Figure 6C). 

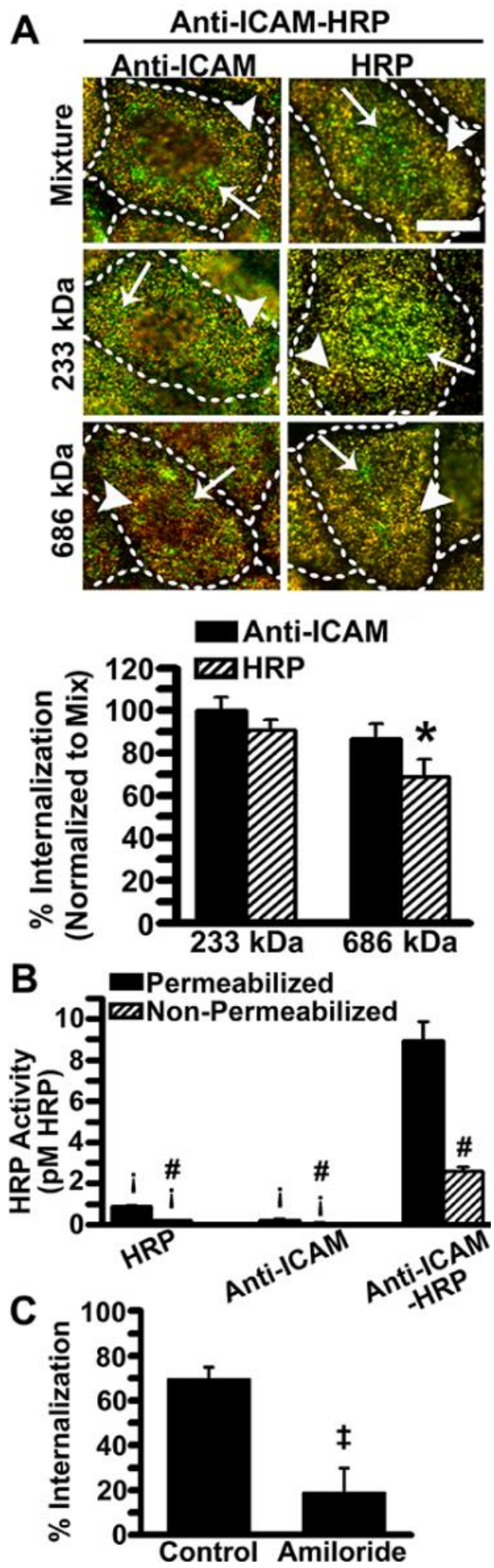

Figure 6. Uptake and activity of anti-ICAM-HRP conjugates in Caco2 cells. The anti-ICAM-HRP conjugate mixture was separated by AF4 into a form corresponding to 1:2 antibody-to-enzyme molar ratio (233 $\mathrm{kDa})$ and a form representing larger multimolecular or aggregated conjugates (686 kDa). (A) Caco-2 cells were incubated with the conjugate mixture vs. each conjugate fraction for a $30 \mathrm{~min}$, washed, and incubated with medium for up to $1 \mathrm{~h}$ to track uptake. Similar to unconjugated antibodies (Figure 1), either surface-bound anti-ICAM or HRP were immunostained to fluoresce in yellow (arrowheads), whereas internalized anti-ICAM or HRP were immunostained to fluoresce in green alone (arrows). Scale bar $=10 \mu \mathrm{m}$. Dashed lines mark the cell borders, observed by phase contrast. The percentage of internalization was obtained as in Figure 1, and normalized to that of the conjugated mixture used as a control (Ctr). (B) Incubations were in the absence or presence of permeabilization. Non-bound conjugates were removed and HRP substrate was added to measure HRP activity (pM HRP) in permeabilized cells (total internalized and cell surface-bound conjugate) vs. non-permeabilized cells (surface-bound fraction). The difference between these two measurements is internalized activity. (C) The percentage of HRP activity internalized with respect to the total cellassociated activity was calculated in cells treated or not with amiloride. Data are Mean \pm S.E.M. * Compares each conjugate fraction against the control mixture; ; compares unconjugated counterparts to anti-ICAMHRP conjugate; \# compares permeabilized to non-permeabilized cells; $\$$ compares amiloride vs. control; ( $\mathrm{p}<0.05$, Student's $t$ test).

\section{Specific transport of active anti-ICAM-enzyme conjugates across cell monolayers.}

Finally, we examined whether anti-ICAM molecules can transport an active cargo across cell monolayers. By measuring the HRP activity of the basolateral fraction, we found that the $233 \mathrm{kDa}$ conjugate, corresponding to species that display a single antibody, delivered 10-fold greater HRP than the $686 \mathrm{kDa}$ 
conjugate and 2.6-fold greater than the unseparated mixture ( $24 \mathrm{~h}$; Figure 7A). The same was true for the rate of transport, $\mathrm{P}_{\mathrm{app}}$, which was 11-fold and 2.4-fold greater for $233 \mathrm{kDa}$ conjugates relative to $686 \mathrm{kDa}$ and unseparated conjugates (Figure 7B). Amiloride-derivative lowered the HRP activity at the basolateral chamber by $60 \%$, and the corresponding $\mathrm{P}_{\text {app }}$ by $92 \%$ (Figure $7 \mathrm{C}$ ). No changes were observed in the permeability barrier during transport of anti-ICAM-HRP conjugates (99\% of control TEER; Figure 7C), suggesting that transport occurred via the vesicular CAM pathway, not paracellular leakage.

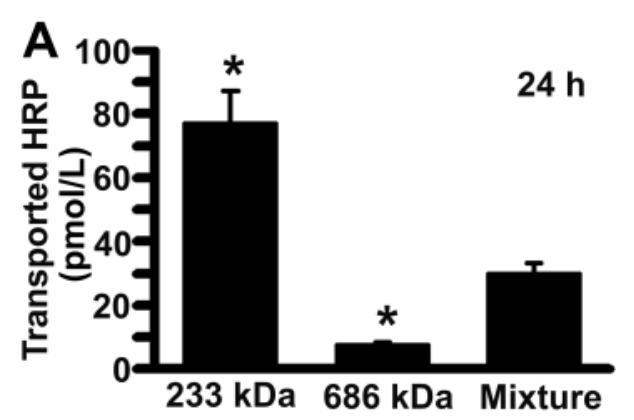

Figure 7. Transepithelial transport of anti-ICAM-HRP conjugates across Caco-2 monolayers. The anti-ICAM-HRP conjugate mixture was separated by AF4 into two molecular weight fractions: a form corresponding to 1:2 antibody-to-enzyme molar ratio $(233 \mathrm{kDa})$ and a form with larger multimolecular or aggregated conjugates $(686 \mathrm{kDa})$. Caco- 2 cells cultured on Transwell@ inserts were incubated with the

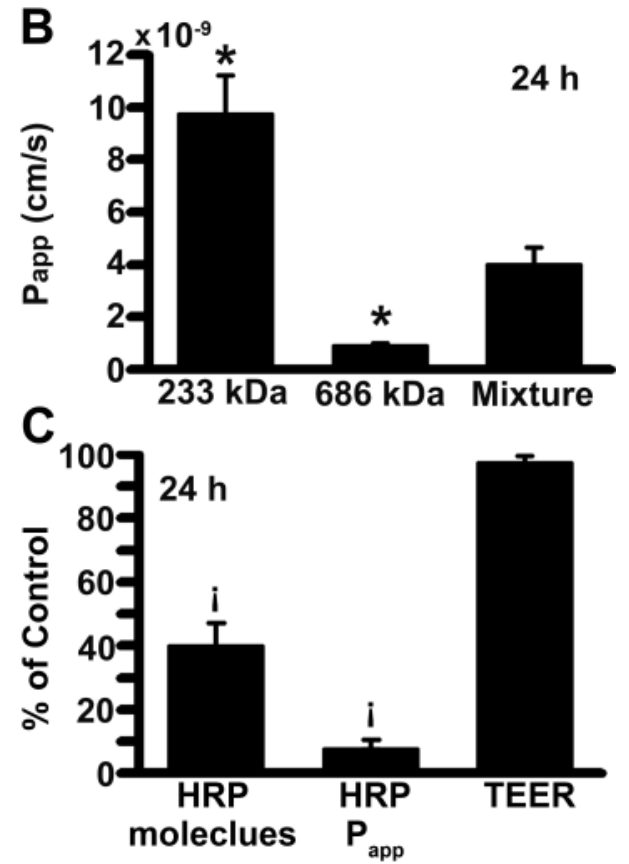
conjugate mixture vs. each conjugate fraction for $24 \mathrm{~h}$ at $37^{\circ} \mathrm{C}$. HRP activity in the basolateral and cell fractions were measured to calculate (A) transported HRP activity (pmol/L), and (B) the rate of transport in terms of $\mathrm{P}_{\text {app. }}$ (C) Incubation with the conjugate mixture was performed in the presence of EIPA to inhibit CAM transcytosis and the HRP activity in the basolateral fraction and permeability coefficient (Papp) were compared to control media. The transepithelial electrical resistance (TEER) after transport in control conditions was compared to the absence of conjugates, as a control for paracellular transport. Data are Mean \pm S.E.M. * Compares values to the unseparated conjugate mixture; $;$ compares amiloride to control ( $\mathrm{p}<0.05$, Student's $t$ test).

\section{DISCUSSION}

Previous studies exploiting endocytosis or transcytosis of therapeutics by targeting ICAM-1 had used nanocarriers or conjugates coupled to multiple copies of anti-ICAM targeting moieties, as multivalent binding was thought necessary to induce transport [8, 9, 17, 19-27]. This work demonstrates for the first 
time that non-multivalent binding to ICAM-1 can also be used to carry active cargoes into and across cells.

First, we verified specific endocytosis of (non-multivalent) anti-ICAM molecules in a variety of cells, including two primary cell types (fibroblasts and endothelial cells [25]) and three established cell lines (A431, Caco-2, SH-S5Y5). These cells belong to different tissues (epithelial, connective, and neural), display normal vs. disease (cancer) phenotypes, and were activated with TNF $\alpha$ or non-activated to mimic inflammation vs. control conditions. Therefore, endocytic uptake of anti-ICAM seems to be a universal phenomenon among cells that express this marker, as previously observed for endocytosis of multivalent anti-ICAM carriers $[8,9,12,17,26]$. Such common uptake of (non-multivalent) anti-ICAM was not expected, because the natural ligands of ICAM-1 bind to cells in a multivalent manner: in nature ICAM-1 is bound by leukocyte $\beta_{2}$ integrins, whereby each leukocyte expresses multiple copies of these molecules on their surface [18]. Since receptors have evolved signaling mechanisms specifically triggered by their natural ligands, varying the binding valency was expected to change the response, as shown for receptors of immunoglobulins, transferrin, and folate [24, 28, 31-34]. However, this aspect may be less important in the case of ICAM-1, as this molecule has been shown to exist on the cell-surface as a monomer, dimer, tetramer, and larger-order oligomers [18]. If (non-multivalent) anti-ICAM binds to oligomeric ICAM-1, this may still be "sensed" by cells as a multimeric interaction as the receptor is already oligomerized. Nevertheless, this remains to be investigated.

In addition, lysosomal trafficking and degradation by anti-ICAM molecules was minimal in Caco-2 cells, in agreement with previous findings for anti-ICAM molecules in endothelial cells [25]. This is in contrast to multivalent anti-ICAM carriers, which had been shown to efficiently reach lysosomes ( $\sim 80 \%$ of the internalized fraction by $5 \mathrm{~h}[19,25])$. Whether this differential lysosomal trafficking of non-multivalent anti-ICAM vs. multivalent anti-ICAM carriers depends on their relative affinity toward the receptor (e.g., their affinity has been reported to be in the nmol/L vs. the pmol/L level respectively [30], remains to be determined. In any instance, this property of multivalent anti-ICAM carriers offers an advantage for treatments necessitating lysosomal delivery, such as recombinant enzymes used to treat lysosomal storage disorders [19, 20, 24], while direct drug coupling to anti-ICAM molecules may offer an alternative destination for treatment of other maladies. In this regard, the final destination of anti-ICAM molecules 
may depend on the biology of the cell type involved. For instance, cell receptors involved in the transport of ligands across cellular barriers possess properly polarized surfaces (apical vs. basolateral) and specific machinery to distinguish both interfaces and enable transcytosis [35]. However, transcytosis is not biologically necessary for tissue cells that do not form a part of these barriers, nor do they have apical vs. abluminal surfaces, and only intracellular routing or recycling is possible in these cells [35]. In agreement with this, we have observed recycling of anti-ICAM molecules when cells were plated on glass coverslips, where transcytosis is not possible due to the lack of a basolateral space [25]. Instead, this work shows that anti-ICAM molecules are transcytosed across cells that have both apical and basolateral interfaces. Thus, it is expected that this strategy can afford transcellular delivery of therapeutics across cellular barriers vs. endocytosis within tissue cells. This was demonstrated in the present study for model (HRP) enzyme conjugates using Transwell@ vs. coverslip models.

Dual trafficking (into and across cells) has been also observed for multivalent anti-ICAM carriers [8, 9, $12,19]$. In both cases (anti-ICAM molecules or anti-ICAM carriers) Transwell@ experiments indicate that a fraction of internalized materials traffics across the cell barrier while another fraction remains associated with the cells $[8,9,12,19]$. The mechanisms that regulate this are currently unknown and will be the focus of our future studies. However, this phenomenon is in agreement with current knowledge about dual transport of natural ligands across cellular linings, such as transferrin, insulin, LDL, etc. [2, 3, 35, 36]. Interestingly, both anti-ICAM molecules and anti-ICAM carriers endured transcytosis albeit different degrees of lysosomal trafficking [25]. This may be due to the different models used to study lysosomal vs. transcytosis transport (coverslips vs. Transwells®) and/or may indicate that transcytosis is a predominant route for the CAM pathway, where lysosomal transport only occurs when transcytosis is not possible (in coverslips).

In conclusion, ICAM-1 targeting may offer interesting delivery versatility, depending on the modality of drug coupling pursued. In this work, direct conjugation of a model enzyme (HRP) to anti-ICAM rendered species bearing a single antibody (233 kDa conjugate) vs. larger species (686 kDa conjugate), both of which were internalized and transcytosed by cells. Yet, transcytosis seemed more efficient for the former species, in agreement with the fact that non-multivalent vs. multivalent anti-ICAM differ in terms of their 
intracellular retention [25]. Importantly, this strategy rendered significant enzyme activity within cells and transported across cells, illustrating its potential in the context of therapeutic delivery.

\section{CONCLUSION}

Whereas previous studies on active ICAM-1 targeting had focused on subcellular transport of multivalent anti-ICAM carriers or highly multimeric protein conjugates [18-27]], this study focused on anti-ICAM molecules, demonstrating that: (1) induction of CAM-mediated endocytosis by anti-ICAM is a common phenomenon among ICAM-1-expressing cells, regardless of origin and disease state, (2) uptake of antiICAM does not lead to lysosomal transport but to transcytosis across cellular barriers, and (3) coupling anti-ICAM to cargo molecules in a manner that renders non-multivalent conjugate species provides intraand trans-cellular delivery of active cargo. Therefore, non-multivalent ICAM-1 targeting serves as an alternative to multivalent forms previously investigated for therapeutic applications, providing transport of active cargoes into and across cells.

\section{ACKNOWLEDGMENTS}

This work was supported by a National Science Foundation Graduate Research Fellowship to R.G. (DGE0750616), and funds awarded to S.M. by the National Institutes of Health (grant R01-HL98416) and the National Science Foundation (CBET-1402756). We thank Dr. Jerrold Turner (Department of Biological Sciences, University of Chicago, IL) for kindly donating Caco-2 cells for this study, and Dr. Edward Schuchman (Department of Genetics and Genomic Sciences, Mount Sinai School of Medicine, NY) for generously sharing wild-type skin fibroblasts.

\section{DISCLOSURE}

The authors report no conflicts of interest in this work. 


\section{REFERENCES}

[1] L. Rajendran, H.J. Knolker, K. Simons, Subcellular targeting strategies for drug design and delivery, Nat Rev Drug Discov, 9 (2010) 29-42.

[2] R. Duncan, S.C. Richardson, Endocytosis and intracellular trafficking as gateways for nanomedicine delivery: opportunities and challenges, Mol Pharm, 9 (2012) 2380-2402.

[3] S. Muro, Challenges in design and characterization of ligand-targeted drug delivery systems, J Control Release, 164 (2012) 125-137.

[4] J.E. Schnitzer, Caveolae: from basic trafficking mechanisms to targeting transcytosis for tissuespecific drug and gene delivery in vivo, Adv Drug Deliv Rev, 49 (2001) 265-280.

[5] E. Neuwelt, N.J. Abbott, L. Abrey, W.A. Banks, B. Blakley, T. Davis, B. Engelhardt, P. Grammas, M. Nedergaard, J. Nutt, W. Pardridge, G.A. Rosenberg, Q. Smith, L.R. Drewes, Strategies to advance translational research into brain barriers, Lancet Neurol, 7 (2008) 84-96.

[6] K. Greish, Enhanced permeability and retention (EPR) effect for anticancer nanomedicine drug targeting, Methods Mol Biol, 624 (2010) 25-37.

[7] F.M. Goycoolea, G. Lollo, C. Remunan-Lopez, F. Quaglia, M.J. Alonso, Chitosan-alginate blended nanoparticles as carriers for the transmucosal delivery of macromolecules, Biomacromolecules, 10 (2009) 1736-1743.

[8] J. Hsu, J. Rappaport, S. Muro, Specific binding, uptake, and transport of ICAM-1-targeted nanocarriers across endothelial and subendothelial cell components of the blood-brain barrier, Pharm Res, 31 (2014) 1855-1866.

[9] R. Ghaffarian, T. Bhowmick, S. Muro, Transport of nanocarriers across gastrointestinal epithelial cells by a new transcellular route induced by targeting ICAM-1, J Control Release, 163 (2012) 25-33.

[10] R.V. Stan, Endocytosis pathways in endothelium: how many?, Am J Physiol Lung Cell Mol Physiol, 290 (2006) L806-808.

[11] D. Serrano, S. Muro, Endothelial Cell Adhesion Molecules and Drug Delivery Applications, in: H. Aranda-Espinoza (Ed.) Mechanobiology of the Endothelium, CRC Press, Boca Raton, 2015, pp. 185-226. [12] S. Muro, R. Wiewrodt, A. Thomas, L. Koniaris, S.M. Albelda, V.R. Muzykantov, M. Koval, A novel endocytic pathway induced by clustering endothelial ICAM-1 or PECAM-1, J Cell Sci, 116 (2003) 15991609.

[13] J.C. Murciano, S. Muro, L. Koniaris, M. Christofidou-Solomidou, D.W. Harshaw, S.M. Albelda, D.N. Granger, D.B. Cines, V.R. Muzykantov, ICAM-directed vascular immunotargeting of antithrombotic agents to the endothelial luminal surface, Blood, 101 (2003) 3977-3984.

[14] C. Garnacho, D. Serrano, S. Muro, A fibrinogen-derived peptide provides intercellular adhesion molecule-1-specific targeting and intraendothelial transport of polymer nanocarriers in human cell cultures and mice, J Pharmacol Exp Ther, 340 (2012) 638-647.

[15] S. Muro, A DNA device that mediates selective endosomal escape and intracellular delivery of drugs and biologicals, Adv Funct Mater, 24 (2014). 
[16] E. Mastrobattista, G. Storm, L. van Bloois, R. Reszka, P.G. Bloemen, D.J. Crommelin, P.A. Henricks, Cellular uptake of liposomes targeted to intercellular adhesion molecule-1 (ICAM-1) on bronchial epithelial cells, Biochim Biophys Acta, 1419 (1999) 353-363.

[17] N. Zhang, C. Chittasupho, C. Duangrat, T.J. Siahaan, C. Berkland, PLGA nanoparticle--peptide conjugate effectively targets intercellular cell-adhesion molecule-1, Bioconjug Chem, 19 (2008) 145-152.

[18] D. Serrano, T. Bhowmick, R. Chadha, C. Garnacho, S. Muro, Intercellular adhesion molecule 1 engagement modulates sphingomyelinase and ceramide, supporting uptake of drug carriers by the vascular endothelium, Arterioscler Thromb Vasc Biol, 32 (2012) 1178-1185.

[19] J. Hsu, L. Northrup, T. Bhowmick, S. Muro, Enhanced delivery of alpha-glucosidase for Pompe disease by ICAM-1-targeted nanocarriers: comparative performance of a strategy for three distinct lysosomal storage disorders, Nanomedicine, 8 (2012) 731-739.

[20] C. Garnacho, R. Dhami, E. Simone, T. Dziubla, J. Leferovich, E.H. Schuchman, V. Muzykantov, S. Muro, Delivery of acid sphingomyelinase in normal and niemann-pick disease mice using intercellular adhesion molecule-1-targeted polymer nanocarriers, J Pharmacol Exp Ther, 325 (2008) 400-408.

[21] K.S. Choi, S.H. Kim, Q.Y. Cai, S.Y. Kim, H.O. Kim, H.J. Lee, E.A. Kim, S.E. Yoon, K.J. Yun, K.H. Yoon, Inflammation-specific T1 imaging using anti-intercellular adhesion molecule 1 antibodyconjugated gadolinium diethylenetriaminepentaacetic acid, Mol Imaging, 6 (2007) 75-84.

[22] G.E. Weller, F.S. Villanueva, E.M. Tom, W.R. Wagner, Targeted ultrasound contrast agents: in vitro assessment of endothelial dysfunction and multi-targeting to ICAM-1 and sialyl Lewisx, Biotechnol Bioeng, 92 (2005) 780-788.

[23] C.F. Greineder, A.M. Chacko, S. Zaytsev, B.J. Zern, R. Carnemolla, E.D. Hood, J. Han, B.S. Ding, C.T. Esmon, V.R. Muzykantov, Vascular immunotargeting to endothelial determinant ICAM-1 enables optimal partnering of recombinant scFv-thrombomodulin fusion with endogenous cofactor, PLoS One, 8 (2013) e80110.

[24] J. Papademetriou, C. Garnacho, D. Serrano, T. Bhowmick, E.H. Schuchman, S. Muro, Comparative binding, endocytosis, and biodistribution of antibodies and antibody-coated carriers for targeted delivery of lysosomal enzymes to ICAM-1 versus transferrin receptor, J Inherit Metab Dis, 36 (2013) 467-477.

[25] R. Ghaffarian, S. Muro, Distinct subcellular trafficking resulting from monomeric vs multimeric targeting to endothelial ICAM-1: implications for drug delivery, Mol Pharm, 11 (2014) 4350-4362.

[26] J. Hsu, J. Hoenicka, S. Muro, Targeting, endocytosis, and lysosomal delivery of active enzymes to model human neurons by ICAM-1-targeted nanocarriers, Pharm Res, 32 (2015) 1264-1278.

[27] S. Muro, Muzykantov, V.R., Murciano, J., Characterization of endothelial internalization and targeting of antibody-enzyme conjugates in cell cultures and in laboratory animals, in: C.M. Niemeyer (Ed.) Methods in molecular biology. Bioconjugation protocols., Humana Press, Totowa, New Jersey, 2004, pp. 21-36.

[28] K.L. Singer, K.E. Mostov, Dimerization of the polymeric immunoglobulin receptor controls its transcytotic trafficking, Mol Biol Cell, 9 (1998) 901-915.

[29] D.W. Shortt, D. Roessner, P. Wyatt, Asbolute measurement of diameter distributions of particles using a multiangle light scattering photometer coupled with flow field-flow fractionation, American laboratory, 28 (1996) 21-28. 
[30] S. Muro, T. Dziubla, W. Qiu, J. Leferovich, X. Cui, E. Berk, V.R. Muzykantov, Endothelial targeting of high-affinity multivalent polymer nanocarriers directed to intercellular adhesion molecule 1, J Pharmacol Exp Ther, 317 (2006) 1161-1169.

[31] E.W. Marsh, P.L. Leopold, N.L. Jones, F.R. Maxfield, Oligomerized transferrin receptors are selectively retained by a lumenal sorting signal in a long-lived endocytic recycling compartment, J Cell Biol, 129 (1995) 1509-1522.

[32] W. Xia, P.S. Low, Folate-targeted therapies for cancer, J Med Chem, 53 (2010) 6811-6824.

[33] P. Oh, P. Borgstrom, H. Witkiewicz, Y. Li, B.J. Borgstrom, A. Chrastina, K. Iwata, K.R. Zinn, R. Baldwin, J.E. Testa, J.E. Schnitzer, Live dynamic imaging of caveolae pumping targeted antibody rapidly and specifically across endothelium in the lung, Nat Biotechnol, 25 (2007) 327-337.

[34] I. Mellman, H. Plutner, Internalization and degradation of macrophage Fc receptors bound to polyvalent immune complexes, J Cell Biol, 98 (1984) 1170-1177.

[35] M. Koval, Structure and function of epithelial and endothelial barriers, in: S. Muro (Ed.) Drug delivery across physiological barriers, Pan Stanford Publishing Pte. Ltd., Singapore, 2016, pp. 3-39.

[36] S. Muro, Strategies for delivery of therapeutics into the central nervous system for treatment of lysosomal storage disorders, Drug Delivery and Translational Research, 2 (2012) 169-186.

Abbreviations: AF4, asymmetric flow field-flow fractionation; Amil., amiloride; BSA, bovine serum albumin; Caco-2, human colorectal adenocarcinoma cells; Fil.; filipin; FITC, fluorescein isothiocyanate; ICAM-1, intercellular adhesion molecule-1; HRP, horseradish peroxidase; HUVEC, human umbilical vein endothelial cells; IgG, immunoglobulin G; MALS, multi-angle light scattering; MDC, monodansylcadaverine; PBS, phosphate buffered saline; QELS, quasi-elastic light scattering; RI, refractive index; TxR, Texas red; TNF $\alpha$, tumor necrosis factor alpha. 


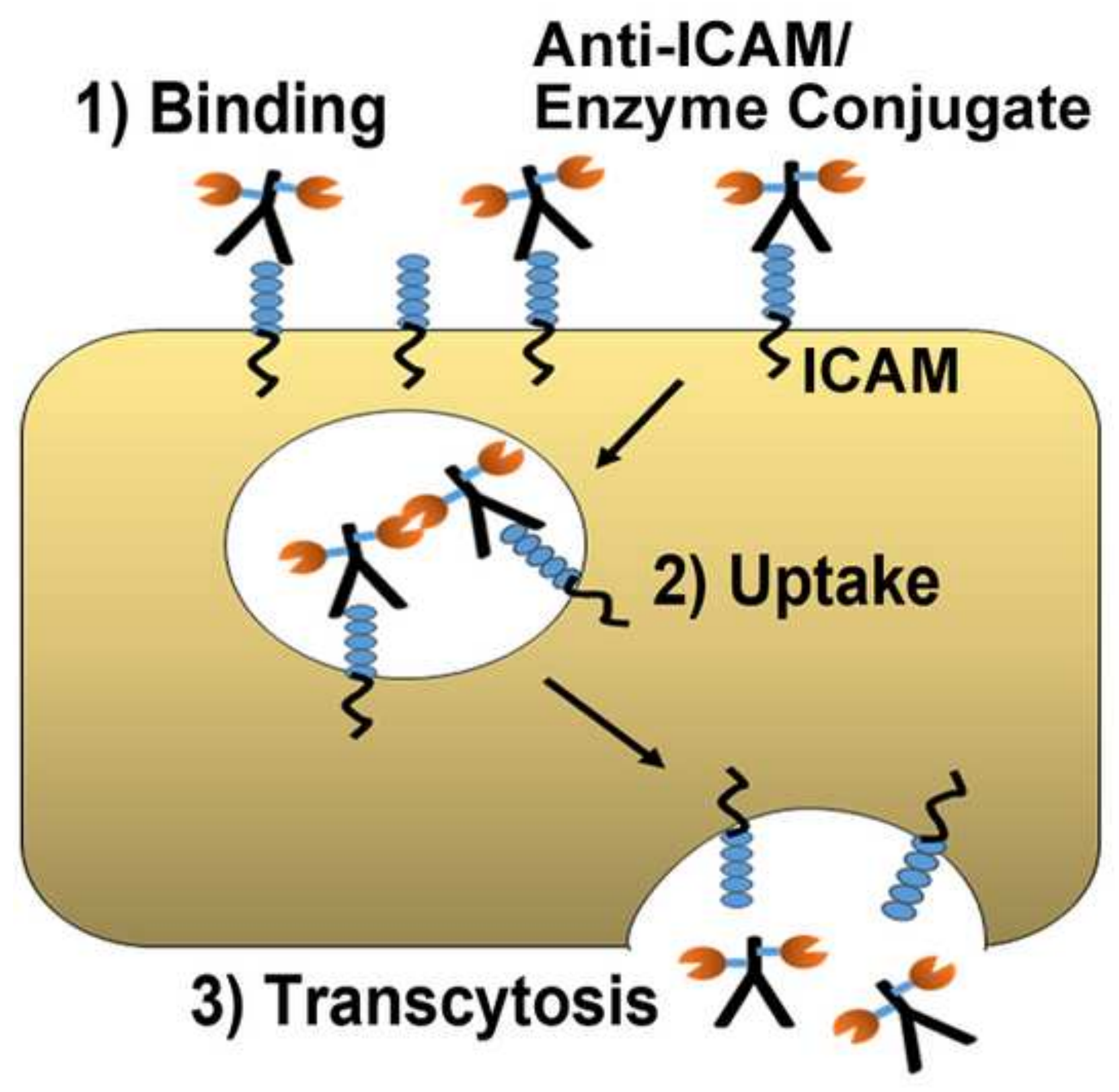

1) Binding

Anti-ICAM/ Enzyme Conjugate

3) Transcytosis

X 